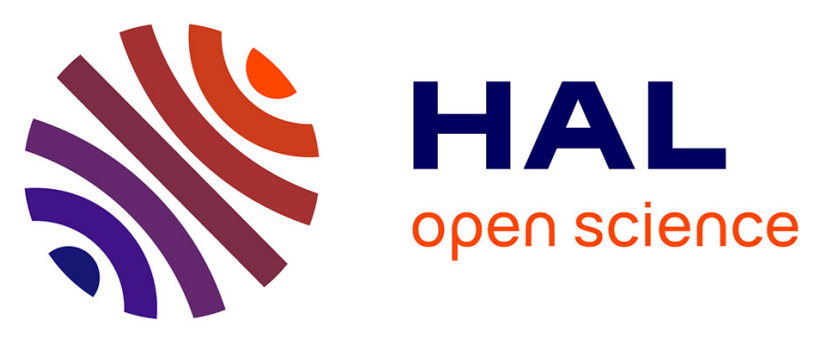

\title{
Utility of enhanced CT for patients with suspected uncomplicated renal colic and no acute findings on non-enhanced CT
}

C. Robert, Y. Gandon, B. Peyronnet, S. Gauthier, C. Aubé, A. Paisant

\section{- To cite this version:}

C. Robert, Y. Gandon, B. Peyronnet, S. Gauthier, C. Aubé, et al.. Utility of enhanced CT for patients with suspected uncomplicated renal colic and no acute findings on non-enhanced CT. Clinical Radiology, 2019, 74, pp.813.e11 - 813.e18. 10.1016/j.crad.2019.06.007 . hal-03488173

\section{HAL Id: hal-03488173 https://hal.science/hal-03488173}

Submitted on 20 Dec 2021

HAL is a multi-disciplinary open access archive for the deposit and dissemination of scientific research documents, whether they are published or not. The documents may come from teaching and research institutions in France or abroad, or from public or private research centers.
L'archive ouverte pluridisciplinaire HAL, est destinée au dépôt et à la diffusion de documents scientifiques de niveau recherche, publiés ou non, émanant des établissements d'enseignement et de recherche français ou étrangers, des laboratoires publics ou privés.

\section{(ㄷ)(1) $\$$}

Distributed under a Creative Commons Attribution - NonCommerciall 4.0 International 
Utility of enhanced CT for patients with suspected uncomplicated renal colic and no acute findings on non-enhanced CT

C. Robert ${ }^{1}$, Y. Gandon ${ }^{1}$, B. Peyronnet ${ }^{2}$, S. Gauthier ${ }^{3}$, C. Aubé ${ }^{4}$, A. Paisant ${ }^{1,4, *}$

1: Department of radiology, Rennes University Hospital, 2 Rue Henry Le Guilloux, 35033 Rennes, France

2: Department of urology, Rennes University Hospital, 2 Rue Henry Le Guilloux, 35033 Rennes, France

3: Emergency department, Rennes University Hospital, 2 Rue Henry Le Guilloux, 35033 Rennes, France

4: Department of radiology, Angers University Hospital, 4 Rue Larrey, 49100 Angers, France

*Guarantor and correspondent: A. Paisant, Department of Radiology, Abdominal Unit, Angers University Hospital, 4 Rue Larrey, 49100 Angers, France. Tel.: +33 241 353637.

E-mail address: anita.paisant@chu-angers.fr phone:

\section{ABSTRACT}

AIM: To evaluate the utility of contrast-enhanced computer tomography (CECT) for patients with suspected uncomplicated renal colic (URC) and no abnormalities on non-enhanced computed tomography (NECT).

MATERIALS AND METHODS: The hospital institutional review board and ethics committee approved this retrospective study with a waiver of informed consent. 
Between January 2016 and April 2017, all consecutive adult patients who consulted at the adult Emergency Department (ED) with suspected URC and who had undergone both NECT and CECT were included retrospectively. The primary endpoint was prevalence of CECT-only diagnosis without acute findings on NECT. The risk factors for an acute finding were identified by logistic regression analysis.

RESULTS: Among 126 patients with suspected URC, 12 were excluded. Among the 76 patients with no acute findings on NECT, CECT led to find acute lesions in 14/76 (18\%) cases, but only $2 / 76(3 \%)$ resulted in a change of management. Predictive factors of abnormal finding on CECT were: low renal clearance and high leukocyte count with OR 0.96 (95\% confidence interval [Cl]: 0.93-0.99), $p=0.0189$ and OR 5.79 (95\% Cl: 1.55-21.64), $p=0.0091$, respectively,.

CONCLUSIONS: In most cases, NECT is sufficient for screening patients with suspected URC. If leucocytosis and low renal function are present, stronger consideration may be given to CECT.

\section{INTRODUCTION}

The lifetime incidence of urolithiasis in Europe is estimated at between 5 and $10 \%$ 1,2. Renal colic is a common presenting symptom in France, with a prevalence of 1$2 \%$ of patients admitted to emergency departments (ED)2. Non-enhanced computed tomography (NECT) is the diagnostic method of choice for patients with suspected renal colic 2-7. NECT is rapid, accurate, and has high sensitivity (96-98\%) and specificity (100\%) 3,8-10; however, in almost $30 \%$ of cases $11-14$, NECT performed for suspected renal colic finds no abnormalities to explain the symptoms. In such cases, an additional acquisition with contrast media injection is often performed in clinical practice to determine the cause of symptoms; however, there is no 
international guideline to provide clear guidance on whether or not it is necessary to perform CECT in cases of negative NECT. In daily practice, when NECT is normal, it is unclear whether radiologists should undertake CECT as a second acquisition or not. Indeed, CECT provides little additional information to explain the patient's pain and any change in management is rarely relevant. This is supported in the literature by two studies, which did not, however, include some clinical data and blood results (such as analogue pain scale, heart rate, urinary dipstick findings, leukocytes, or Creactive protein $[\mathrm{CRP}]$ ) in their analyses 15,16 . Therefore, the management of these patients often depends on the radiologist's appreciation and experience and differs between hospitals. When no acute finding explain symptoms on NECT in cases of suspected URC, in addition to normal clinical and biological findings, CECT is not necessary. In addition, contrast medium injection carries significant risks that should be taken into consideration, particularly in young patients (additional radiation exposure, renal and allergy risks, time and cost).

The aim of the present study was to determine the utility of CECT in patients with suspected URC with no acute findings explaining symptoms on NECT by evaluating the prevalence of CECT-only diagnosis, without acute findings on NECT. A secondary objective was to determine clinical and biological prognostic factors associated with a finding at CECT.

\section{MATERIALS AND METHODS}

The hospital institutional review board and ethics committee approved this retrospective study with a waiver of informed consent.

Patients 
Between January 2016 and April 2017, all consecutive adult patients who presented to the adult ED and were referred by the emergency physician for a CT for suspected URC were included. Four hundred and fifty-seven patients were review for inclusion in the final cohort (Fig. 1).

\section{Study design}

Informatics data from all patients referred to the radiology department for CT during a representative period of $>1$ year were reviewed retrospectively. Patients with confirmed nephrolithiasis on NECT or those who only had NECT were excluded from analysis. Departmental policy was to perform CECT in patients referred for URC, if NECT did not identify the cause of clinical symptoms. Patients who underwent both NECT and CECT, where the NECT did not demonstrate an acute finding were included in the current analysis. Patients were excluded from analysis if they had a temperature of $>38^{\circ} \mathrm{C}\left(100^{\circ} \mathrm{F}\right)$, have known structural urinary tract abnormality including solitary kidney, or had recent history of abdominal surgery. Finally, patients with "no acute findings" on NECT were analysed.

\section{Data collected}

Data collected included patient demographics (gender, age), clinical data (analogue pain scale on admission, flank pain, dysuria, heart rate, temperature), blood results (creatinine $[\mathrm{mmol} / \mathrm{l}]$, renal clearance $[\mathrm{ml} / \mathrm{min}]$, leukocytes [10\%/], C-reactive protein [CRP; mg/l], urinary dipstick findings [leukocytes, erythrocytes, nitrites; positive if 1+]) collected from patients' files during the time in ED. The CT protocol, radiation doses, pathology results, and treatment were also recorded. The final ED physician or urologist conclusion acted as the standard of reference. If patients were re-admitted 
to the ED in the following month, the reason for re-admission was recorded and again conclusions were taken as standard reference if the symptoms were similar.

Imaging

CT was performed using a 64-detector row system, LightSpeed VCT 64 (GE Medical Systems, Milwaukee, WI, USA), from the diaphragm to the symphysis pubis with 1.375 pitch, 0.6 seconds tube rotation time, $100 \mathrm{kV}$, a nominal section thickness of $0.625 \mathrm{~mm}$, and a reconstructed section thickness of $1.25 \mathrm{~mm}$. Dose-modulation software was used to determine the tube current according to body weight (noise index, $25 ; 100-300 \mathrm{~mA})$.

Another scanner, Aquilon Prime (Toshiba Otawara, Japan), was used for some patients (24/76), with 0.825 pitch, 0.5 seconds tube rotation time, $100 \mathrm{kV}$, and a nominal and reconstructed section thickness of $2 \mathrm{~mm}$. Dose-modulation software was also used to determine the tube current according to body weight (noise index, 12.5; 80-500 mA).

Images were first acquired without contrast agent. An iodinated contrast agent (Xenetix 300, Guerbet) was then administered intravenously at a dose of $1.5 \mathrm{ml} / \mathrm{kg}$ and a flow rate of 3-4 ml/s using a mechanical power injector (One Medrad Drive, Indianola, PA, USA). Images were acquired in the portal phase (80-90 seconds after injection) with the same CT parameters except for the $120 \mathrm{kV}$. An additional arterial (40 seconds) or excretory phase (8-12 minutes) was at the radiologist's discretion.

\section{CT interpretation}

Retrospectively, one senior (6 years of experience in emergency radiology) and one junior radiologist (4 years of experience in emergency radiology) independently 
reviewed each CT on the department's PACS workstation (Telemis HQ Belgium, Telemis SA) with multiplanar reconstructions. The radiologists were provided with the information "suspected URC", as well as clinical and biological data, but were blind to the final diagnosis. Each radiologist performed two different readings: (1) the first reading included the NECT of each patient only. Each radiologist classified patients into two groups: "no acute findings" and "acute findings". An acute finding was defined as any CT abnormality explaining the symptoms and related to emergency findings. Incidental findings considered as not related to the patient's symptoms were not included in acute findings. If there was disagreement in the classification of a case, a joint review was done. The present study population consisted of all patients with no acute findings on NECT (Fig. 1). (2) The second reading was performed randomly 1 month after the first one and included both NECT and CECT images for each patient in the study population. The final diagnosis was taken as that diagnosed with NECT and CECT imaging. If there was disagreement in the final diagnosis, a joint review was done. Each diagnosis was associated with a confidence level at each reading session, ranging between 0 and $100 \%$.

\section{Treatment}

Patients were treated by an emergency physician. A change in medical care was defined as a patient receiving a treatment different from treatment based on clinical and biological emergency physician examination, as analyses were done on patients with NECT with no acute findings. A relevant change in medical care was defined as a patient being hospitalised.

Statistical analysis 
Quantitative variables are presented as mean \pm standard deviation. For qualitative variables, the number $(\mathrm{N})$ and percentage (\%) are presented for each category. Logistic regressions were used to perform univariate and multivariate analyses to identify predictive factors for acute findings, and are presented by OR and $95 \% \mathrm{Cl}$.

Each observer's level of confidence (before the consensus reading) was compared between the two readings using a Wilcoxon signed-rank test. The analysis was done with version 9.4 of SAS software (SAS Institute, Cary, NC, USA).

\section{RESULTS}

Population

Among the 126 patients having both NECT and CECT, 12 were excluded. The reasons for exclusion are given in Figure 1. Of the 114 patients included, 76 had no acute findings on NECT explaining symptoms (Fig. 1). The mean age of patients was 40.8 years (SD 15.7, range 18-85 years), and $30 \%$ of patients were male. The population characteristics are shown in Table 1.

No acute findings on NECT and CECT

Sixty-two patients had no acute findings on either NECT or CECT. Twenty-one patients had a positive urinary dipstick test (positive leukocytes) and five of them were treated with antibiotics. All other patients received symptomatic treatment. At 1 month follow-up, two female patients had been admitted within 10 days to the gynaecology department and subsequently discharged with symptomatic treatment. One patient returned to the ED because of seizure, and one patient was admitted for pulmonary embolism diagnosed at chest CT. 
Acute findings on CECT only

Among the 76 patients, 14 (18\%) had acute findings on CECT only (Fig. 1). In these 14 patients, the diagnosis included pyelitis and ureteritis $(n=7)$, cystitis $(n=1)$, ureteral ectasia $(n=1)$, renal infarct $(n=1)$, appendicitis $(n=1)$, diverticulitis $(n=1)$, duodenojejunitis $(n=1)$, and adnexal pathology $(n=1)$. Eight of these patients had no change in medical care with only symptomatic treatment. In four cases, a diagnosis of urinary tract infection was established, combining a positive urinary dipstick and abnormalities on CECT. The patients received antibiotic treatment. For two patients (3\%), CECT led to a relevant change in medical care and the patients were admitted to hospital. One of these patients with appendicitis had surgery and the other patient with renal infarct was treated with anticoagulant therapy. On 1-month follow-up, one patient was re-admitted within 10 days as a gynaecological emergency and then discharged with symptomatic treatment, and one patient returned to the ED for quinolone tendinitis.

Factors predictive of CECT abnormalities

In the univariate analysis, ORs for acute findings on CECT were statistically significant for three variables (Table 2). The first was low renal clearance: 89.6 (SD 22.5) versus 104.8 (SD 18.5) $\mathrm{ml} / \mathrm{min}(\mathrm{OR} 0.9695 \% \mathrm{Cl}: 0.93-0.99 ; p=0.02$ ). The second was a leukocyte threshold $>12 \times 10^{9} / \mathrm{l}$, which is more common in patients with CT abnormalities (OR $5.79,95 \% \mathrm{Cl}: 1.55-21.64 ; p=0.01$ ). The third was a CRP value $>5 \mathrm{mg} / \mathrm{l}$ (OR 4.36, 95\% Cl: 1.12-17.03; $p=0.03$ ).

On multivariate analysis, only renal clearance and a leukocyte threshold $>12 \times 10^{9} / 1$ were statistically significant with ORs of $0.95(95 \% \mathrm{Cl}: 0.92-0.99 ; p=0.01)$ and 0.11 (95\% Cl: 0.03-0.48; $p<0.01)$, respectively. 
Confidence level

The diagnostic confidence level for both the senior and junior radiologist was significantly better $(p<0.0001)$ with NECT+CECT images than with NECT images only. The results are shown in Table 3 . The senior radiologist was more confident than the junior radiologist for NECT images. This difference disappeared when the CECT series was added.

\section{DISCUSSION}

In the present study, 62/76 (81\%) of patients who underwent enhanced CT for suspected URC had both a negative NECT and a negative CECT. In 14/76 (18\%) of cases, there were acute findings on CECT only. The change in medical care was only relevant for $2 / 76(3 \%)$ of patients.

There is no clear guidance on whether to perform CECT if NECT performed for suspected URC is normal 6,17. Agarwal et al. and Miller et al. attempted to address this question, but yielded discordant results. In their studies, CECT provided additional information in $5.3 \%$ and $9.9 \%$ of cases, respectively.

Other urological conditions are the main alternative diagnoses with the additional CECT acquisition, as described in other studies 15,16. Nine patients had pyelitis, ureteritis, cystitis, or ureteral ectasia on CECT suggestive of a recent history of ureteral stone or urinary tract infection. In these cases, CECT did provide a definitive diagnosis, but the rate of medical care modified by acute findings was low in the present study. In four patients, a change in medical care was deemed to have occurred according to the present criteria, due to treatment with antibiotics; however, in these patients, the dipstick test was also abnormal. Five patients with no NECT 
and CECT abnormalities were also prescribed antibiotics subsequent to dipstick results. This constitutes one of the limitations of the study: due to its retrospective nature, it is difficult to determine whether the CECT actually changed management or whether the positive dipstick alone would have been sufficient for the treatment. According to guidelines, a positive dipstick test with corresponding abdominal pain should be sufficient for antibiotic treatment. Therefore, management probably did not change as a result of CECT results, and patients would still have received antibiotics on the basis of clinical and biological findings.

The change in medical care was relevant for two patients, one with appendicitis and another with a renal infarction. In the case of appendicitis, the clinical examination found right flank pain in the 18-year-old male patient, and biological abnormalities (elevated CRP). In cases such as this with young patients, CT should not be the primary imaging method for abdominal exploration. Ultrasound remains the main imaging method for right flank pain in young patients, which was not performed for this patient before CT and may have established the correct diagnosis of appendicitis (Fig. 2). Moreover, the NECT of this patient was reviewed after the study analysis by both readers and there was no sign to suspect appendicitis on NECT (the appendix was surrounded by the ileum and no infiltration or size augmentation was seen on the NECT image). In the second case of renal infarction, the patient was older (80 years) with many cardiovascular risk factors. Analysis of medical records showed that the patient had been hospitalised in the previous month to receive ablative therapy for atrial fibrillation. This procedure is known to carry a high risk of embolic events, especially in renal arteries (Fig. 3). The recent medical history should have steered clinical suspicion in ED away from URC and towards renal ischaemia. The radiologist 
should have suspected a vascular pathology because the patient had arterial and venous phases on CECT.

Two factors associated with a CECT-only diagnosis were identified. First, a leukocyte count greater than a threshold value of $12 \times 10^{9} / \mathrm{l}$ was associated with CECT abnormalities. This could be explained by the fact that urinary and gastrointestinal tract inflammation increases the white blood cell count. Second, the renal clearance is associated with an $\mathrm{OR}<1$ means that the variable represents a protection from the outcome. So, a low renal clearance is associated with CECT abnormalities, which is not surprising as the main alternative diagnosis in the present study was other urological conditions. Interestingly, the urinalysis was not associated with a CECTonly diagnosis 18; however, the sample size was small and results should be confirmed in a larger study.

The present results show that, in cases of suspected URC, performing CECT when NECT is normal is of low benefit. This should be taken into consideration in clinical practice due to the significant risks associated with contrast medium injection. First, CECT imaging represents additional radiation exposure as it is not possible to perform only CECT in these patients, given that kidney stones show up better on NECT. So if an injection is required, two acquisitions should be performed, one NECT and one CECT. Moreover, the NECT may be "low-dose" whereas the CECT is usually performed with normal radiation doses in clinical practice 19,20 . Second, this poses a renal risk in these patients for whom the main alternative diagnosis is a urological condition. Third, there is a contrast medium allergy risk, especially in young patients in whom the benefit-risk ratio should be continuously assessed. Finally, the time delay and the cost should also be considered. One possibility that could be 
considered is performing an initial "low-dose" NECT and a repeat clinical examination to identify pain in particular (some patients no longer had pain after the CT).

For both observers, CECT was associated with a higher confidence level than NECT. The senior radiologist's confidence level in the NECT was higher than that of the junior; however, this did not affect performance.

There were limitations of the present study that should be considered. The small sample size and the retrospective design can introduce selection bias. Some patients admitted to the ED for URC with no acute findings on NECT images did not undergo CECT for various reasons (radiologist's discretion, clinical impression, or absence of pain during examination, etc.). Patients who were injected were the most symptomatic; in which case, many abnormalities would be expected on CECT and a high benefit with contrast medium injection; however, the CECT images provided little additional information.

In conclusion, it is suggested that in cases of suspected URC with no atypical clinical and biological features, a normal NECT should not be routinely followed by CECT; however, CECT must be considered if leucocytosis and low renal clearance are present.

\section{ACKNOWLEDGEMENTS}

The authors thank Dr Coralie Doudnikoff (Department of Ophthalmology, Rennes University Hospital) for her contribution to data collection and Mrs Chloe Rousseau (Department of Public Health, Rennes University Hospital) for her contribution to data analysis. 


\section{REFERENCES}

1. Bartoletti R, Cai T, Mondaini N, et al. Epidemiology and risk factors in urolithiasis. Urol Int 2007;79(1):3-7. https://doi.org/10.1159/000104434.

2. El Khebir M, Fougeras O, Le Gall C, et al. Updating 2008 of 8th Conference of consensus of the French Society of medical emergencies of 1999. The treatment of adult renal colic by the emergency services and in ER. Prog En Urol 2009;19(7):46273. https://doi.org/10.1016/j.purol.2009.03.005.

3. Smith RC, Rosenfield AT, Choe KA, et al. Acute flank pain: comparison of noncontrast-enhanced CT and intravenous urography. Radiology 1995;194(3):789-794.

4. Fulgham PF, Assimos DG, Pearle MS, Preminger GM. Clinical effectiveness protocols for imaging in the management of ureteral calculous disease: AUA Technology Assessment. J Urol 2013;189(4):1203-13. https://doi.org/10.1016/j.juro.2012.10.031.

5. Worster A, Preyra I, Weaver B, Haines T. The accuracy of noncontrast helical computed tomography versus intravenous pyelography in the diagnosis of suspected acute urolithiasis: a meta-analysis. Ann Emerg Med 2002;40(3):280-6. https://doi.org/10.1067/mem.2002.126170.

6. Bultitude M, Rees J. Management of renal colic. BMJ 2012;345(aug29 1):e5499_ e5499. https://doi.org/10.1136/bmj.e5499.

7. Coursey CA, Casalino DD, Remer EM, et al. ACR Appropriateness Criteria® acute onset flank pain-suspicion of stone disease. Ultrasound Q 2012;28(3):227233. 
8. Fielding JR, Steele G, Fox LA, Heller H, Loughlin KR. Spiral computerized tomography in the evaluation of acute flank pain: a replacement for excretory urography. J Urol. 1997 Jun;157(6):2071-3.

9. Miller OF, Rineer SK, Reichard SR, et al. Prospective comparison of unenhanced spiral computed tomography and intravenous urogram in the evaluation of acute flank pain. Urology 1998;52(6):982-987.

10. Sourtzis S, Thibeau JF, Damry N, Raslan A, Vandendris M, Bellemans M. Radiologic investigation of renal colic: unenhanced helical CT compared with excretory urography. AJR Am J Roentgenol 1999;172(6):1491-1494.

11. Katz DS, Scheer M, Lumerman JH, Mellinger BC, Stillman CA, Lane MJ. Alternative or additional diagnoses on unenhanced helical computed tomography for suspected renal colic: experience with 1000 consecutive examinations. Urology 2000;56(1):53-57.

12. Kirpalani A, Khalili K, Lee S, Haider MA. Renal colic: comparison of use and outcomes of unenhanced helical CT for emergency investigation in 1998 and 2002. Radiology 2005;236(2):554-8. https://doi.org/10.1148/radiol.2362040887.

13. Cullen IM, Cafferty F, Oon SF, et al. Evaluation of suspected renal colic with noncontrast CT in the emergency department: a single institution study. J Endourol 2008;22(11):2441-6. https://doi.org/10.1089/end.2008.0120.

14. Chowdhury FU, Kotwal S, Raghunathan G, Wah TM, Joyce A, Irving HC. Unenhanced multidetector CT (CT KUB) in the initial imaging of suspected acute renal colic: evaluating a new service. Clin Radiol 2007;62(10):970-7. https://doi.org/10.1016/j.crad.2007.04.016. 
15. Miller FH, Kraemer E, Dalal K, Keppke A, Huo E, Hoff FL. Unexplained renal colic: what is the utility of IV contrast? Clin Imaging 2005;29(5):331-6. https://doi.org/10.1016/j.clinimag.2005.01.002.

16. Agarwal MD, Levenson RB, Siewert B, Camacho MA, Raptopoulos V. Limited added utility of performing follow-up contrast-enhanced CT in patients undergoing initial non-enhanced CT for evaluation of flank pain in the emergency department. Emerg Radiol 2015;22(2):109-15. https://doi.org/10.1007/s10140-014-1259-4.

17. Chabannes é., Bensalah K, Carpentier X, et al. Management of adult's renal and ureteral stones. Update of the Lithiasis Committee of the French association of urology (CLAFU). General considerations. Prog En Urol 2013;23(16):1389-99. https://doi.org/10.1016/j.purol.2013.08.315.

18. Desai V, Cox M, Deshmukh S, Roth CG. Contrast-enhanced or noncontrast CT for renal colic: utilizing urinalysis and patient history of urolithiasis to decide. Emerg Radiol 2018;25(5):455-60. https://doi.org/10.1007/s10140-018-1604-0.

19. Kalra MK, Maher MM, Toth TL, et al. Strategies for CT radiation dose optimization. Radiology $2004 ; 230(3): 619-28$. https://doi.org/10.1148/radiol.2303021726.

20. Frush DP, Slack CC, Hollingsworth CL, et al. Computer-simulated radiation dose reduction for abdominal multidetector CT of pediatric patients. AJR Am J Roentgenol 2002;179(5):1107-13. https://doi.org/10.2214/ajr.179.5.1791107.

Fig 1. Flow chart. URC, uncomplicated renal colic; NECT, non-enhanced computed tomography; CECT, contrast-enhanced computed tomography. 
Fig. 2. An 18-year-old male patient with right flank pain, no fever, and elevated CRP (60 mg/l). (a) No abnormality is seen at NECT. (b) Early appendicitis is diagnosed at CECT (arrow).

Fig. 3. An 80-year-old patient with left flank pain, many cardiovascular risk factors, and a recent history of atrial fibrillation ablation. (a) No abnormality is seen at NECT in left kidney. (b) No contrast medium uptake is seen at CECT in the left kidney consistent with infarct (asterisk). (c) There is a thrombus (arrow) at the origin of the left renal artery. No contrast medium uptake in the left kidney is seen compared to the right kidney

Table 1. Population characteristics

\begin{tabular}{|c|c|c|c|c|}
\hline Patient characteristics & All $(n=76)$ & $\begin{array}{l}\text { No } \\
\text { abnormalities } \\
(n=62)\end{array}$ & \multicolumn{2}{|c|}{ Acute findings $(n=14)$} \\
\hline \multicolumn{5}{|l|}{ Gender } \\
\hline Female & & $53(69.7 \%)$ & $42(67.7 \%)$ & $11(78.6 \%)$ \\
\hline $\begin{array}{c}\text { Male } \\
\end{array}$ & & $23(30.3 \%)$ & $20(32.3 \%)$ & $3(21.4 \%)$ \\
\hline Age (mean, SD) & & $40.8 \pm 15.7$ & $40.2 \pm 15.2$ & $43.1 \pm 18.1$ \\
\hline \multicolumn{5}{|l|}{ Medical care } \\
\hline \begin{tabular}{|c|} 
Antibiotics \\
\end{tabular} & & $9(11.8 \%)$ & $5(8.1 \%)$ & $4(28.6 \%)$ \\
\hline Anticoagulants & & $2(2.6 \%)$ & $1(1.6 \%)$ & $1(7.1 \%)$ \\
\hline Surgery & & $1(1.3 \%)$ & $0(0.0 \%)$ & $1(7.1 \%)$ \\
\hline Symptomatic & & $64(84.2 \%)$ & $56(90.3 \%)$ & $8(57.1 \%)$ \\
\hline \multicolumn{5}{|c|}{ Re-admitted within 10 days } \\
\hline \begin{tabular}{|l|} 
No \\
\end{tabular} & & $71(93.4 \%)$ & $59(95.2 \%)$ & $12(85.7 \%)$ \\
\hline Yes & & $5(6.6 \%)$ & $3(4.8 \%)$ & $2(14.3 \%)$ \\
\hline Analog pain scale on ac & ission & $6.2 \pm 2.5$ & $6.0 \pm 2.6$ & $7.1 \pm 2.2$ \\
\hline \multicolumn{5}{|c|}{ Dysuria } \\
\hline No & & $51(68.9 \%)$ & $41(67.2 \%)$ & $10(76.9 \%)$ \\
\hline \begin{tabular}{|c|} 
Yes \\
\end{tabular} & & $23(31.1 \%)$ & $20(32.8 \%)$ & $3(23.1 \%)$ \\
\hline Heart rate (mean, SD) & & $81.2 \pm 16.3$ & $81.4 \pm 16.5$ & $80.4 \pm 15.8$ \\
\hline \multicolumn{5}{|l|}{ Flank pain } \\
\hline Both sides & & $7(9.2 \%)$ & $5(8.1 \%)$ & $2(14.3 \%)$ \\
\hline Right & & $39(51.3 \%)$ & $29(46.8 \%)$ & $10(71.4 \%)$ \\
\hline \begin{tabular}{|c|} 
Left \\
\end{tabular} & & $30(39.5 \%)$ & $28(45.2 \%)$ & $2(14.3 \%)$ \\
\hline Temperature $\left({ }^{\circ} \mathrm{C}\right)$ (mea & SD) & $36.7 \pm 0.5$ & $36.7 \pm 0.5$ & $36.6 \pm 0.6$ \\
\hline
\end{tabular}




\begin{tabular}{|c|c|c|c|}
\hline \begin{tabular}{|l|l} 
Patient characteristics $\quad$ All $(n=76)$ \\
\end{tabular} & $\begin{array}{l}\text { No } \\
\text { abnormalities } \\
(n=62)\end{array}$ & \multicolumn{2}{|c|}{ Acute findings $(n=14)$} \\
\hline Creatinine $(\mu \mathrm{mol} / \mathrm{l})$ (mean, SD) & $71.2 \pm 20.1$ & $68.9 \pm 16.7$ & $81.3 \pm 29.5$ \\
\hline Renal clearance $(\mathrm{ml} / \mathrm{min})$ & $101.9 \pm 20.0$ & $104.8 \pm 18.5$ & $89.6 \pm 22.5$ \\
\hline Leukocytes $\left(10^{9} / I\right)$ & $9.0 \pm 3.1$ & $8.7 \pm 2.8$ & $10.7 \pm 3.9$ \\
\hline C-reactive protein $(\mathrm{mg} / \mathrm{l})$ & $7.9 \pm 18.6$ & $6.6 \pm 18.6$ & $13.8 \pm 18.5$ \\
\hline \multicolumn{4}{|l|}{ Urinary dipstick: leukocytes } \\
\hline 0 & $52(69.3 \%)$ & $42(68.9 \%)$ & $10(71.4 \%)$ \\
\hline 1 & $16(21.3 \%)$ & $15(24.6 \%)$ & $1(7.1 \%)$ \\
\hline 2 & $5(6.7 \%)$ & $3(4.9 \%)$ & $2(14.3 \%)$ \\
\hline 3 & $2(2.7 \%)$ & $1(1.6 \%)$ & $1(7.1 \%)$ \\
\hline \multicolumn{4}{|l|}{ Urinary dipstick: erythrocytes } \\
\hline 0 & $29(38.7 \%)$ & $26(42.6 \%)$ & $3(21.4 \%)$ \\
\hline 1 & $12(16.0 \%)$ & $9(14.8 \%)$ & $3(21.4 \%)$ \\
\hline 2 & $9(12.0 \%)$ & $9(14.8 \%)$ & $0(0.0 \%)$ \\
\hline 3 & $25(33.3 \%)$ & $17(27.9 \%)$ & $8(57.1 \%)$ \\
\hline \multicolumn{4}{|l|}{ Urinary dipstick: nitrites } \\
\hline No & $72(96.0 \%)$ & $60(98.4 \%)$ & $12(85.7 \%)$ \\
\hline Yes & $3(4.0 \%)$ & $1(1.6 \%)$ & $2(14.3 \%)$ \\
\hline $\begin{array}{l}\begin{array}{l}\text { Dose-length product } \\
\text { (mean, SD) }\end{array} \\
\end{array}$ & $568.0 \pm 257.3$ & $578.9 \pm 272.5$ & $519.7 \pm 175.0$ \\
\hline
\end{tabular}

Table 2. Univariate data analysis by logistic regression

\begin{tabular}{|c|l|l|l|l|}
\hline & $\begin{array}{l}\text { Total } \\
(n)\end{array}$ & $\begin{array}{l}\text { Acute } \\
\text { findings } \\
(n)\end{array}$ & OR $[95 \% \mathrm{Cl}]$ & p-Value \\
\hline Variable & 76 & 14 & & 0.43 \\
\hline Gender & 53 & 11 & 1 & \\
\hline Female & 23 & 3 & $0.57[0.14 ; 2.28]$ & \\
\hline Male & 76 & 14 & $1.01[0.98 ; 1.05]$ & 0.53 \\
\hline Age & 76 & 14 & & 0.22 \\
\hline Re-admitted within 10 days & 71 & 12 & 1 & \\
\hline No & 5 & 2 & $3.28[0.49 ; 21.78]$ & \\
\hline Yes & 76 & 14 & $1.20[0.92 ; 1.55]$ & 0.18 \\
\hline Analog pain scale on admission & 74 & 13 & & 0.50 \\
\hline Dysuria & 51 & 10 & 1 & \\
\hline No & 23 & 3 & $0.62[0.15 ; 2.49]$ & \\
\hline Yes & 75 & 14 & & 0.59 \\
\hline Heart rate & 23 & 3 & 1 & \\
\hline$<75$ & 29 & 7 & $2.12[0.48 ; 9.34]$ & \\
\hline $75-85$ & 23 & 4 & $1.40[0.28 ; 7.12]$ & \\
\hline$\geq 85$ & 76 & 14 & & 0.14 \\
\hline Flank pain & 39 & 10 & 1 & \\
\hline Right & 7 & 2 & $1.16[0.19 ; 6.95]$ & \\
\hline Both & & & & \\
\hline
\end{tabular}




\begin{tabular}{|l|l|l|l|l|}
\hline & Total & $\begin{array}{l}\text { Acute } \\
\text { findings } \\
(n)\end{array}$ & OR $[95 \%$ Cl] & $p$-Value \\
\hline Variable & 30 & 2 & $0.21[0.04 ; 1.03]$ & \\
\hline Left & 76 & 14 & $0.64[0.22 ; 1.84]$ & 0.41 \\
\hline Temperature & 75 & 14 & $1.03[1.00 ; 1.05]$ & 0.07 \\
\hline Renatinine & 75 & 14 & $0.96[0.93 ; 0.99]$ & 0.02 \\
\hline Leukocytearance & 75 & 14 & & 0.01 \\
\hline$<12$ & 62 & 8 & 1 & \\
\hline$\geq 12$ & 13 & 6 & $5.79[1.55 ; 21.64]$ & \\
\hline C-reactive protein & 62 & 11 & & $p=0.03$ \\
\hline$\leq 5$ & 45 & 5 & 1 & \\
\hline$>5$ & 17 & 6 & $4.36[1.12 ; 17.03]$ & \\
\hline Urinary dipstick: leukocytes & 75 & 14 & & $p=0.29$ \\
\hline 0 & 52 & 10 & 1 & \\
\hline 1 & 16 & 1 & $0.28[0.03 ; 2.38]$ & \\
\hline 2 & 5 & 2 & $2.80[0.41 ; 19.05]$ & \\
\hline 3 & 2 & 1 & $4.20[0.24 ; 73.07]$ & \\
\hline Urinary dipstick: erythrocytes & 75 & 14 & & $p=0.20$ \\
\hline 0 & 29 & 3 & 1 & \\
\hline 1 & 12 & 3 & $2.79[0.51 ; 15.37]$ & \\
\hline 2 & 9 & 0 & $0.40[0.02 ; 9.82]$ & \\
\hline 3 & 25 & 8 & $3.68[0.90 ; 15.04]$ & \\
\hline Urinary dipstick: nitrites & 75 & 14 & & $p=0.07$ \\
\hline No & 72 & 12 & 1 & \\
\hline Yes & 3 & 2 & $10.00[0.84 ; 119.31]$ & \\
\hline
\end{tabular}

Table 3. Comparison of confidence level between the two readings for each observer

\begin{tabular}{|l|l|l|l|}
\hline Observer & NECT $(n=76)$ & NECT+CECT $(n=76)$ & $p$-Value \\
\hline $\begin{array}{l}\text { \% confidence level of } \\
\text { senior radiologist }\end{array}$ & $88.947 \pm 7.272$ & $98.882 \pm 6.250$ & $\begin{array}{l}p<0.0001 \\
(\mathrm{RS})\end{array}$ \\
\hline & $\begin{array}{l}(60 ; 87.5 ; 90 ; 95 ;(50 ; 100 ; 100 ; 100 ; 100) \\
95)\end{array}$ & & \\
\hline $\begin{array}{l}\text { \% confidence level of } 84.605 \pm 6.417 \\
\text { junior radiologist }\end{array}$ & $99.079 \pm 4.059$ & $\begin{array}{l}p<0.0001 \\
(\mathrm{RS})\end{array}$ \\
\hline & $(60 ; 80 ; 90 ; 90 ; 90)$ & $(80 ; 100 ; 100 ; 100 ; 100)$ & \\
\hline
\end{tabular}
Mean \pm standard deviation (min; Q1; median; Q3; max), Wilcoxon signed-rank test. (RS).

NECT, non-enhanced computed tomography; CECT, contrast-enhanced computed tomography. 


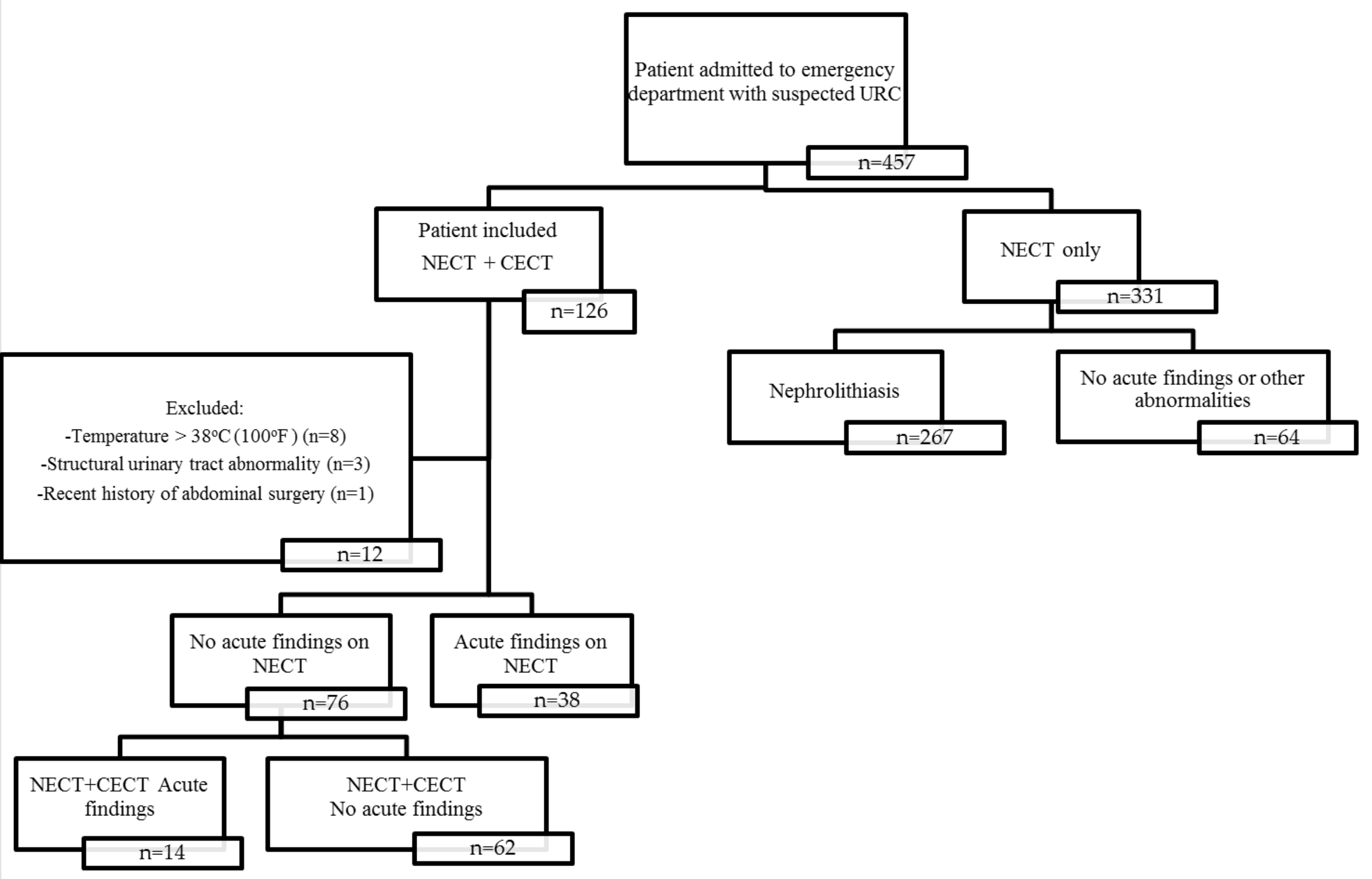




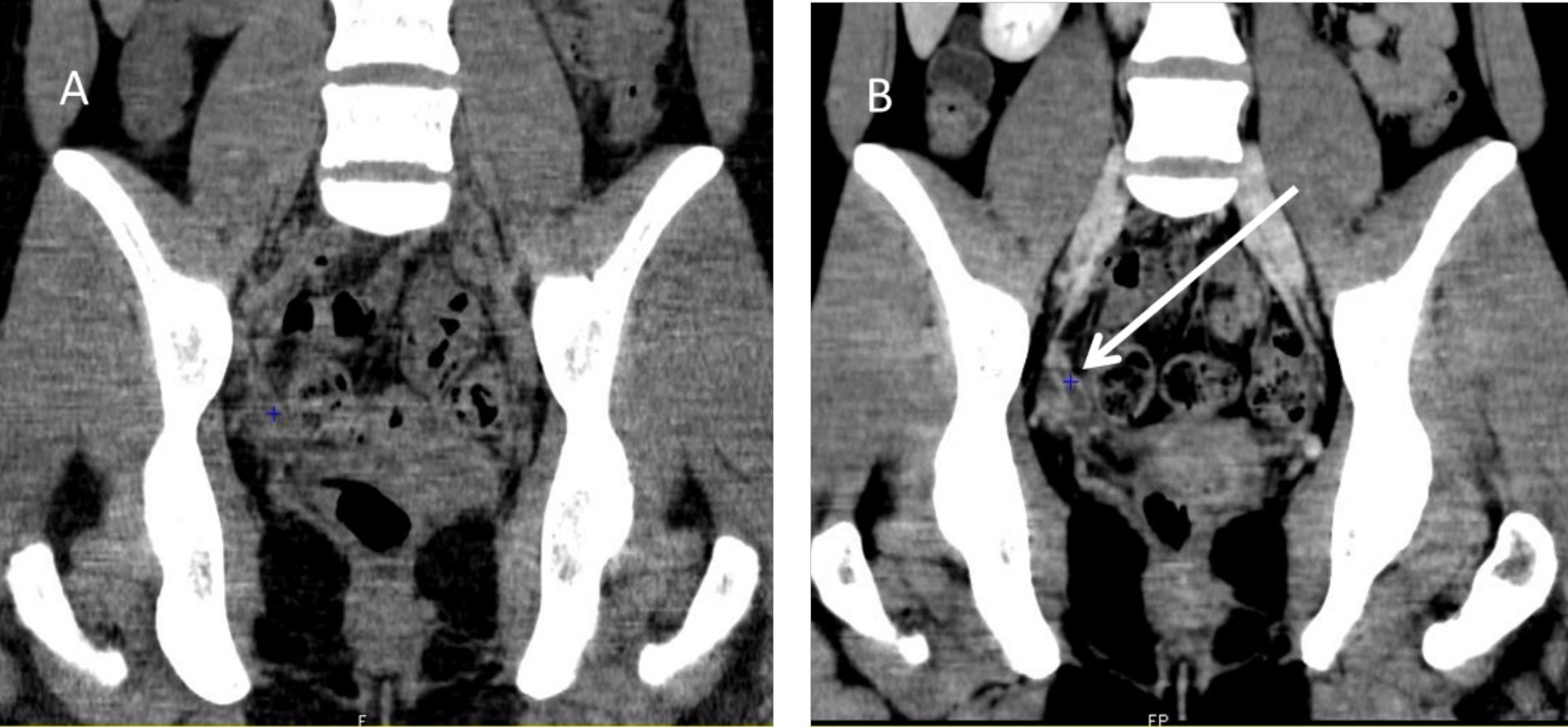




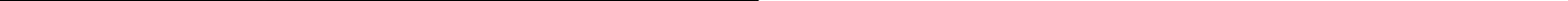

